\title{
STUDI KELAYAKAN USAHATANI KOPI DAN KARAKTERISTIK RUMAH TANGGA USAHATANI KOPI DI KABUPATEN OGAN KOMERING ULU SELATAN
}

\author{
ECONOMIC FEASIBILITY OF THE COFFEE FARMING \\ AND THE CHARACTERISTICS OF THE HOUSEHOLD COFFEE FARMERS \\ IN OGAN KOMERING ULU SELATAN REGENCY
}

\author{
Dana Megayani* \\ Badan Pusat Statistik Provinsi Sumatera Selatan, Palembang \\ *Corresponding email: dana@bps.go.id \\ (Diterima 24-11-2018; Disetujui 13-01-2019)
}

\begin{abstract}
ABSTRAK
Kabupaten Ogan Komering Ulu Selatan (OKUS) merupakan salah satu wilayah dengan luas lahan kopi terbesar di Sumatera Selatan. Bahkan ketika sektor perkebunan menurun, jumlah rumah tangga (ruta) usahatani kopi di kabupaten ini tetap meningkat sebesar 7,63 persen berdasarkan Sensus Pertanian (ST) tahun 2013 dibandingkan dengan ST 2003. Pertanyaannya, apakah usahatani kopi di OKUS memang menguntungkan, sehingga tetap terjadi peningkatan jumlah ruta? Untuk menggambarkan karakteristik petani dan menganalisis kelayakan usaha tani kopi di OKUS dilakukan kajian terhadap data hasil Survei Ongkos UsahaTani Khusus Perkebunan tahun 2014 dengan unit analisis usahatani kopi menggunakan metode analisis deskriptif dan kuantitatif R/C Rasio. Hasilnya, usahatani kopi di OKUS dapat dikatakan layak terutama pada aspek hukum, sosial ekonomi dan finansial. Tetapi para petani masih lemah dalam teknis dan manajemen usaha karena masih menjalankan pola pengelolaan tradisional. Secara demografi, petani kopi didominasi lakilaki berpendidikan rendah dan setiap ruta memiliki pohon rata-rata sejumlah 1.000-3.000 pohon dengan umur tanam kopi 8-15 tahun. Tempat tinggal para petani kopi tergolong baik. Kajian ini merekomendasikan perlunya peningkatan kelembagaan dan pemberdayaan petani kopi tradisional dan strategi pengembangan usahatani kopi, baik dari pihak petani, perusahaan terkait, maupun pemerintah daerah, agar hasil produksi kopi di OKUS lebih berkualitas.
\end{abstract}

Kata kunci: Analisis Kelayakan, Perkebunan, Petani Kopi, Survei Ongkos Usaha Tani (SOUT)

\begin{abstract}
Ogan Komering Ulu Selatan (OKUS) is one of the regencies in South Sumatera with the largest coffee plantation area. Despite the decrease in the plantation sector, the number of household coffee farmers increased by 7.63 percent, based on the Agriculture Cencus of 2013, compared to that of 2003. The question is whether the coffee farming profitable for the farmers. To describe the farmers characteristics and to analyze the economic feasibility of the coffee farming in OKUS, the study on the data obtained from the Cost-Benefit Coffee Farming Survey (SOUT) of the 2014 was carried out using descriptive and quantitative analysis of $R / C$ Ratio. As a result, the coffee farming is profitable and feasible especially in terms of legal, social and economical aspects. However, the farmers are still weak in the technical and business management aspect, due to their traditional management practises. Demographically, the farmers are dominated by low-educated men and each household farmer manages 1,000-3,000 coffee trees with the tree age in between 8 and 15 years. The household housings are categorically as good. This study reccommends an effort of institutional empowerment and capacity building on the farmers as well as a strategy in the agriculture activity, either in the farmers, the associated companies, and the local government, in order to increase the quality of the coffee production.
\end{abstract}

Keywords: Feasibility Analysis, Plantation, Coffee Farmers, Cost-Benefit Farming Survey (SOUT) 


\section{STUDI KELAYAKAN USAHATANI KOPI DAN KARAKTERISTIK RUMAH TANGGA \\ USAHATANI KOPI DI KABUPATEN OGAN KOMERING ULU SELATAN \\ Dana Megayani}

\section{PENDAHULUAN}

Sektor pertanian khususnya subsektor perkebunan termasuk sektor mayoritas lapangan usaha penduduk Indonesia. Salah satu subsektor pertanian yang mempengaruhi perekonomian adalah perkebunan. Untuk komoditi perkebunan yang cukup penting adalah kopi (Nopriyandi dan Haryadi, 2017). Kopi merupakan salah satu komoditi dari subsektor perkebunan yang memegang peranan penting bagi perekonomian nasional, khususnya sebagai sumber devisa, penyedia lapangan kerja dan sebagai sumber pendapatan bagi petani maupun bagi pelaku ekonomi lainnya yang terlibat dalam budidaya, pengolahan dan pemasaran hasil kopi, terutama di daerah-daerah sentra produksi kopi seperti Sumatera Selatan, Lampung, Sumatera Utara dan Jawa Timur (Turnip, 2002).

Hasil Sensus Pertanian 2013 BPS menunjukkan bahwa luas tanaman kopi yang diusahakan/dikelola di Sumatera Selatan seluas 252,90 ribu hektar. Berdasarkan data dari Dinas Perkebunan Provinsi Sumatera Selatan, pada tahun 2012 produksi kopi sebanyak 143,33 ribu ton. Jika dibandingkan dengan negara penghasil kopi lainnya seperti Vietnam dan Brazil, hasil produksi kopi ini masih kalah bersaing. Masalah yang dihadapi dalam pembangunan perkebunan kopi adalah produktivitas dan mutu hasil yang masih rendah (Hariance dkk, 2016).

Hal ini disebabkan karena belum maksimalnya pengelolaan usahatani perkebunan kopi dalam penerapan teknologi maju terutama penggunaan benih unggul yang bermutu, pupuk, pengendalian hama, penyakit dan gulma, serta penanganan panen dan pasca panen. Di samping masih rendahnya tingkat kemampuan SDM dan lemahnya kelembagaan petani yang ada, harga ratarata pemasaran kopi yang masih belum stabil juga menjadi permasalahan dalam perkembangan tanaman kopi. Jenis yang paling banyak diusahakan di Sumatera Selatan adalah jenis kopi robusta, dan di pasar dunia kopi robusta membanjiri pasaran terutama kopi robusta produksi Brazil dan Vietnam. Harga jual yang belum stabil menyebabkan perkembangan tanaman kopi masih belum terlalu signifikan (Kaizan dkk, 2014).

Hasil ST 2013 menunjukkan bahwa sebagian besar perkebunan kopi tersebut diusahakan oleh rumah tangga pertanian secara tradisional. Perkembangan kopi di Sumatera Selatan cukup baik yang ditandai dengan semakin meningkatnya 
jumlah tanaman yang diusahakan. Dari keseluruhan jumlah pohon yang diusahakan/dikelola di tahun 2013, sebanyak 92,01 persen merupakan tanaman yang sudah berproduksi atau menghasilkan. Hal ini menunjukkan bahwa tanaman kopi di Sumatera Selatan merupakan tanaman produktif yang memberikan produksi yang cukup besar.

Berbeda halnya dengan jumlah pohon yang diusahakan yang mengalami peningkatan, jumlah rumah tangga yang mengusahakan tanaman kopi di Sumsel mengalami penurunan selama sepuluh tahun terakhir. Pada tahun 2003 terdapat sebanyak 211,26 ribu rumah tangga turun menjadi 178,67 ribu rumah tangga di tahun 2013. Hal ini dikarenakan sebagian rumah tangga perkebunan kopi di Sumsel tersebut beralih ke komoditi karet. Jika ditinjau per kabupaten/kota, maka Kabupaten Ogan Komering Ulu Selatan (OKUS) merupakan sentra kopi di Sumatera Selatan. Hasil pencacahan lengkap Sensus Pertanian 2013 menunjukkan bahwa di OKUS justru terjadi peningkatan sebanyak 4,39 ribu rumah tangga usaha pertanian $(7,63$ persen) dibandingkan Sensus Pertanian 2003. Petani kopi di OKUS ini mencapai 61.973 rumah tangga atau sekitar sepertiga dari total petani kopi di Sumsel.
Penelitian terkait sosial ekonomi petani kopi di Sumsel terutama di OKUS masih sangat minim padahal komoditi kopi ini banyak diusahakan. Hal ini menimbulkan pertanyaan apakah usahatani kopi di OKUS memang benar menguntungkan, sehingga tetap terjadi peningkatan jumlah ruta usahatani kopi?

Adapun tujuan penelitian ini untuk mengetahui bagaimana karakteristik petani kopi dan menganalisis usahatani dan tingkat kelayakan usahatani kopi di OKUS.

\section{METODE PENELITIAN}

Berdasarkan tujuan yang akan dicapai dalam penelitian ini, maka metode yang dapat digunakan adalah metode deskriptif dan kuantitatif untuk menggambarkan keadaan/karakteristik petani dan menganalisis keuntungan dan kelayakan usahatani kopi di OKUS.

Data yang dikumpulkan terdiri atas data primer dan data sekunder. Data primer diperoleh dari data mentah hasil Survei Ongkos Usahatani (SOUT) untuk subsektor perkebunan yang terakhir dilakukan Badan Pusat Statistik pada tahun 2014.

Jumlah sampel yang diambil 728 rumah tangga (ruta) usahatani kopi tetapi terdapat non respon 12 ruta sehingga total 


\section{STUDI KELAYAKAN USAHATANI KOPI DAN KARAKTERISTIK RUMAH TANGGA \\ USAHATANI KOPI DI KABUPATEN OGAN KOMERING ULU SELATAN \\ Dana Megayani}

data yang digunakan sebanyak 716 ruta petani kopi. Pengambilan sampel SOUT ini secara acak sehingga dapat mewakili keadaan dari seluruh petani kopi di kabupaten OKUS terkait keadaan usahatani mereka di tahun 2014. Sedangkan data sekunder lainnya diperoleh melalui publikasi BPS dan informasi dari data instansi terkait.

Analisis data dilakukan secara deskriptif dari hasil Sensus Pertanian di Sumatera Selatan, dan hasil tabulasi silang data menggunakan SPSS 20.0 dari data mentah SOUT perkebunan komoditi kopi kabupaten OKUS untuk mengetahui keadaan demografis, nilai produksi, ongkos/biaya produksi, keterangan usaha terkait status lahan, sistem tanam, sertifikasi benih dan dampak perubahan iklim serta keterangan umum usaha lainnya. Analisis kuantitatif dilakukan untuk mengukur atau menilai kelayakan finansial pertanian kopi di OKUS dengan beberapa kriteria yang digunakan $\mathrm{R} / \mathrm{C}$ rasio.

\section{HASIL DAN PEMBAHASAN}

Analisis usahatani kopi di OKUS dilakukan berdasarkan data tabulasi menunjukkan keadaan demografi petani Kopi di OKUS dilihat dari jenis kelamin dan tingkat pendidikan. Petani kopi
OKUS secara keseluruhan didominasi oleh laki-laki mencapai 94,41 persen, sedangkan perempuan hanya sekitar 5 persen lebih.

Dilihat dari umur petani, petani kopi di OKUS terdapat hampir 10 persen pada usia lanjut atau umur 60 tahun ke atas $(9,78$ persen $)$. Umur ini tentu mempengaruhi produktifitas petani tetapi sisi lainnya pengalaman lansia dalam mengelola pertaniannya menjadi ilmu uang berharga. Mardani (2017) menyatakan bahwa umur merupakan salah satu faktor yang mempengaruhi petani dalam menjalankan usahanya. Umur petani akan mempengaruhi kemampuan fisik bekerja dan cara berfikir.

Apabila dilihat dari tingkat pendidikan, petani kopi di OKUS separuh lebih hanya tamatan $\mathrm{SD}$, seperempat lebih petani kopi tamatan SMP dan hanya 10 persen lebih tamatan SMU ke atas.

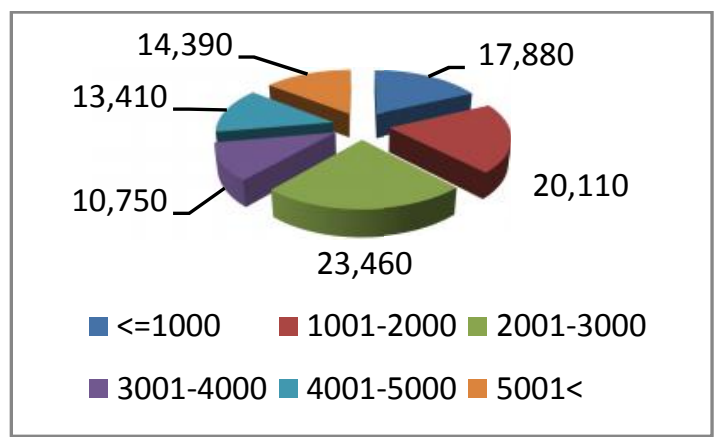

Gambar 1. Persentase Petani Kopi Menurut Kelompok Jumlah Pohon Kopi Dimiliki 
Petani Kopi di OKUS ini umumnya mengusahakan lebih dari 1.000 hingga 3.000 pohon setiap petani mencapai 43,57 persen. Ada 17,88 persen petani kopi yang mengusahakan kopi kurang dari 1.000 pohon. Yang mempunyai pohon lebih dari 3.000 juga cukup banyak, mencapai 38 persen lebih, disajikan pada Gambar 1.

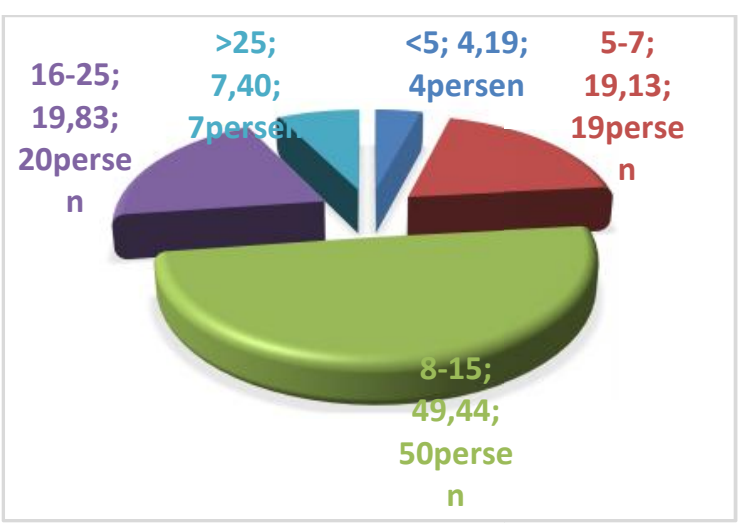

Gambar 2. Persentase Petani Kopi Menurut Kelompok Umur Tanaman Kopi yang Dipunyai di Kabupaten OKUS, 2014

Salah satu karakteristik yang penting untuk diketahui adalah umur tanaman yang ada di kabupaten OKUS. Diketahui bahwa umur tanaman kopi yang dianggap produktif menghasilkan adalah 2-15 tahun (Najiyati 1997). Pada kenyataannya di OKUS terdapat juga tanaman kopi yang masih menghasilkan setelah umur 15 tahun, bahkan untuk umur tanaman 25 tahun ke atas masih ada 7,40 persen dari total petani kopi yang ada di OKUS. Namun, pada umumnya petani kopi di
OKUS memiliki kopi dengan umur tanam 8-15 tahun.

Untuk keadaan umum pertanian kopi di OKUS cukup menarik dibahas. Ternyata hanya 1,82 persen petani kopi yang menggunakan benih bersertifikat. Pada umumnya tanaman kopi terkena organisme pengganggu sebanyak 86,17 persen petani kopi. Ada 2,23 persen petani kopi melakukan integrasi dengan usaha peternakan.

Untuk kelembagaan pun masih sangat kecil persentase petani kopi di OKUS yang menjadi anggota KUD, asosiasi petani dan juga melakukan kemitraan dengan perusahaan perkebunan. Keadaan umum usaha petani kopi ini dapat dilihat pada rangkuman Tabel 1.

Keadaan perumahan atau tempat tinggal petani kopi di OKUS dari hasil olahan SOUT 2014 ternyata pada umumnya sudah baik, ini disimpulkan dari status kepemilikan rumah 90 persen lebih milik sendiri, lantai bukan tanah mencapai 93 persen lebih, atap genteng 53 persen lebih, dinding permanen juga mencapai 91 persen lebih, hampir separuh dari petani kopi mempunyai listrik PLN dan begitu pula fasilitas buang air besar yaitu jamban sendiri pun mencapai 62 persen lebih. 


\section{STUDI KELAYAKAN USAHATANI KOPI DAN KARAKTERISTIK RUMAH TANGGA USAHATANI KOPI DI KABUPATEN OGAN KOMERING ULU SELATAN \\ Dana Megayani}

Tabel 1. Persentase Petani Kopi Menurut Keadaan Umum Usahatani di OKUS, 2014

\begin{tabular}{|c|c|c|}
\hline \multirow{2}{*}{$\begin{array}{l}\text { Keterangan Umum } \\
\text { Usaha Petani Kopi }\end{array}$} & \multicolumn{2}{|c|}{ Persentase } \\
\hline & Ya & Tidak \\
\hline $\begin{array}{l}\text { Penggunaan Benih } \\
\text { Bersertifikat }\end{array}$ & 1,82 & 98,18 \\
\hline $\begin{array}{l}\text { Terkena Organisme } \\
\text { Pengganggu Tanaman }\end{array}$ & 86,17 & 13,83 \\
\hline $\begin{array}{l}\text { Terkena Dampak } \\
\text { Perubahan Iklim atau } \\
\text { Bencana Alam }\end{array}$ & 20,81 & 79,19 \\
\hline $\begin{array}{l}\text { Integrasi dengan Usaha } \\
\text { Peternakan }\end{array}$ & 2,23 & 97,77 \\
\hline $\begin{array}{l}\text { Ada ART yang } \\
\text { memperoleh } \\
\text { penyuluhan/bimbingan } \\
\text { mengenai pengelolaan } \\
\text { usaha kopi }\end{array}$ & 2,23 & 97,77 \\
\hline $\begin{array}{l}\text { Ada ART yang menjadi } \\
\text { anggota KUD atau } \\
\text { Koperasi Perkebunan }\end{array}$ & 0,14 & 99,86 \\
\hline $\begin{array}{l}\text { Ada ART yang menjadi } \\
\text { anggota kelompok tani } \\
\text { kopi }\end{array}$ & 12,85 & 87,15 \\
\hline $\begin{array}{l}\text { Ada ART yang menjadi } \\
\text { anggota asosiasi petani } \\
\text { Kopi }\end{array}$ & 0,14 & 99,86 \\
\hline $\begin{array}{l}\text { Melakukan Kemitraan } \\
\text { dengan Perusahaan } \\
\text { Perkebunan }\end{array}$ & 0,56 & 99,44 \\
\hline $\begin{array}{l}\text { Melakukan Pengolahan } \\
\text { Hasil usaha }\end{array}$ & 95,81 & 4,19 \\
\hline $\begin{array}{l}\text { Mengalami Kesulitan } \\
\text { Pemasaran }\end{array}$ & 19,69 & 80,31 \\
\hline
\end{tabular}

Pada umumnya di daerah pedesaan memang masih menggunakan kayu untuk memasak, begitu pula petani kopi di OKUS masih mencapai 75 persen lebih. Untuk sumber air minum petani kopi di OKUS didominasi oleh sumur dan mata air berturut-turut 41,20 persen dan 37,71 persen.

\section{Analisis Usaha dan Kelayakan}

Usaha yang layak harus dianalisis dari segi hukum, teknis, sosial ekonomi, finansial dan manajemen. Dari sisi hukum, tidak bertentangan dengan peraturan dan norma yang berlaku. Di OKUS ini tidak terjadi permasalahan hukum terutama persoalan lahan pertanian yang mencuat karena pada umumnya usahatani rumah tangga yang menguasai lahan di OKUS.

Kelayakan secara teknis usahatani kopi di OKUS telah berlangsung lama berarti secara teknis dapat dilaksanakan dengan baik dan lancar walaupun kurang memanfaatkan teknologi. Hal ini diketahui dari penggunaan benih yang bersertifikat sangat kecil dan banyak tanaman kopi yang terkena hama/ pengganggu lainnya, selain itu petani didominasi orang yang tidak pernah menerima penyuluhan atau pelatihan mengenai pengelolaan usahatani kopi berarti teknisnya berdasarkan pengalaman turun temurun.

Secara sosial ekonomi, usahatani kopi di OKUS selama ini disinyalir telah memberi manfaat terhadap masyarakat sehingga usahatani kopi ini telah berjalan turun menurun dan terus meningkat jumlah yang mengusahakannya dibanding 10 tahun yang lalu. Untuk 
kelayakan finansial menghasilkan arus kas positif yang dapat menutup semua kewajiban dan memberikan keuntungan dapat dilihat pada analisis dengan perhitungan pada sub bahasan berikutnya. Manajemen usahatani rumah tangga dikatakan layak apabila usahatani dapat dikelola dengan baik, tetapi secara rinci tidak dilakukan pada penelitian ini mengenai manajemen secara mendalam tetapi dari analisis deskripsi mengenai integrasi kelembagaan dan kemitraan petani sangat minim sehingga pada umumnya mengalami kesulitan terutama manajemen pemasaran. Ini mestinya memberi peluang kepada perusahaan atau investor untuk memodernisasi pertanian kopi dan kekuatan sinergi bersama petani (Saputra 2015).Terkait manajemen SDM petani yang masih tradisional, keselamatan kerja tentu tidak pernah dipedulikan (Fanggi 2016).

Untuk analisis finansial, hasil usahatani diperoleh dari seluruh nilai produksi kopi yang diterima oleh responden, sedangkan pendapatan diperoleh dari selisih antara penerimaan dengan total biaya usahatani yang dikeluarkan. Adapun dari sisi pengeluaran/biaya (C) yang dimaksud sudah memperhitungkan perkiraan upah buruh walaupun menggunakan pekerja keluarga dan perkiraan sewa lahan dan peralatan besar serta penyusutan untuk biaya tetap.

Tabel 2. Rata-rata Pendapatan per Hektar Lahan Perkebunan Kopi di OKUS

\begin{tabular}{cccc}
\hline $\begin{array}{c}\text { R atau } \\
\text { Nilai } \\
\text { Produksi } \\
\text { (000 Rp) }\end{array}$ & $\begin{array}{c}\text { C atau } \\
\text { Pengeluaran } \\
(\mathbf{0 0 0} \text { Rp) }\end{array}$ & $\begin{array}{c}\text { B atau } \\
\text { Pendapatan } \\
(\mathbf{0 0 0} \text { Rp) }\end{array}$ & R/C \\
\hline $7.874,97$ & $4.885,18$ & $2.989,79$ & $\mathbf{1 , 6 1}$ \\
\hline Sumber: Diolah dari SOUT & 2014, BPS & \\
Pada & Tabel 2 & disajikan rata-rata
\end{tabular}
pendapatan petani kopi di OKUS. Selanjutnya rata-rata pendapatan petani kopi di atas merupakan hasil perhitungan dalam satu tahun yang hampir setiap bulan ada kopi yang dipanen. Dari Tabel 2 terlihat jelas bahwa setelah dilakukan analisis pendapatan menunjukkan bahwa rata-rata pendapatan $(\mathrm{R})$ yang diperoleh petani kopi sebesar Rp 2.989.790 per hektar. Ini berarti bahwa adanya keuntungan/manfaat yang diperoleh ratarata petani di OKUS apalagi dalam berusahatani kopi tidak memerlukan banyak biaya pengeluaran karena tidak menggunakan pupuk dan pestisida serta untuk pembibitan menggunakan bibit dari pohon yang sudah ada sebelumnya karena sistem budidaya untuk tanaman kopi hanya dengan menggunakan stek atau batang dari pohon induk.

Berdasarkan hasil penelitian yang dilakukan terhadap petani kopi di kabupaten OKUS, pada Tabel 3 terlihat 


\section{STUDI KELAYAKAN USAHATANI KOPI DAN KARAKTERISTIK RUMAH TANGGA \\ USAHATANI KOPI DI KABUPATEN OGAN KOMERING ULU SELATAN \\ Dana Megayani}

bahwa nilai $\mathrm{R} / \mathrm{C}$ rasio lebih besar dari satu, yaitu sebesar 1,61. Ini berarti bahwa usahatani kopi di OKUS menguntungkan dan layak untuk diusahakan. Selanjutnya nilai $\mathrm{R} / \mathrm{C}$ rasio sebesar 1,61 menunjukkan bahwa untuk setiap peningkatan biaya pengeluaran dalam berusaha tani kopi di OKUS sebesar Rp 100 maka penerimaan akan meningkat sebesar Rp 161. Untuk setiap peningkatan pengeluaran biaya usaha tani sebesar Rp 100 yang artinya setiap Rp 100 yang diinvestasikan petani kopi akan memperoleh penerimaan sebesar Rp 161.

Soeliyanto, 2010 mengemukakan bahwa kriteria keuntungan dengan indikator $\mathrm{R} / \mathrm{C}>1$ dianggap menguntungkan dan layak diusahakan. Berdasarkan pendapat inilah maka dengan nilai $\mathrm{R} / \mathrm{C}$ rasio sebesar 1,61 ini mengindikasikan bahwa usahatani kopi pada di OKUS layak untuk diusahakan, karena mendatangkan keuntungan bagi petani. Dari sisi manfaat, B/C positif semua karena petani kopi dalam analisis ini sudah menghasilkan semua sehingga untuk pengeluaran awal atau saat investasi yang mestinya pendapatan masih negatif tidak ada datanya sehingga tidak dapat dilakukan analisis B/C Rasio.

Perhitungan analisis keuntungan dan kelayakan usahatani menurut umur tanaman kopi, tabulasi per tahun ternyata terjadi fluktuasi dan distribusi data tidak normal tetapi ada kecenderungan keuntungan naik di awal umur tanam (sebelum 5 tahun) sehingga dikelompokkan pada kecenderungan pendapatannya dan dibentuk agar distribusi per kelompok umur tanam menjadi normal (minimal sampel 30).

Apabila dikelompokkan menurut umur tanaman disesuaikan kemiripan pendapatan per hektar dan memperhitungkan kenormalan sampel maka diketahui bahwa pada kelompok umur tanaman 5-7 tahun paling menguntungkan dengan $\mathrm{R} / \mathrm{C}$ rasio 1,98 atau keuntungan hampir 2 kali lipat. Diketahui secara serial umur tanaman sudah mulai menguntungkan di tahun awal tanam 1 tahun lebih sampai kurang dari 5 tahun dan keuntungan marginal terus bertambah hingga tahun ke 7 , lalu tahun ke 8 tetap mendapatkan keuntungan masih cukup banyak tetapi sudah tidak sebanyak tahun awal sampai tahun ke 7, dan terus menurun. Uniknya lagi tanaman kopi ini dari kelompok umur yang > 25 tahun pun tetap mendapatkan $\mathrm{R} / \mathrm{C}$ lebih dari 1 sehingga memang dapat dikatakan usahatani kopi di OKUS layak dan menguntungkan (Tabel 3). 
Tabel 3. Rata-rata Pendapatan per Hektar Tanaman yang Menghasilkan dari Usahatani Kopi Menurut Umur Tanaman di OKUS

\begin{tabular}{ccccc}
\hline Umur Tanaman & Nilai Produksi & Total Biaya & Pendapatan & R/C \\
\hline$<5$ & 9.012 .244 & 5.451 .174 & 3.561 .070 & 1,65 \\
\hline $5-7$ & 9.292 .591 & 4.691 .523 & 4.601 .067 & 1,98 \\
\hline $8-15$ & 8.757 .755 & 5.565 .750 & 3.192 .005 & 1,57 \\
\hline $16-25$ & 8.530 .804 & 5.593 .229 & 2.937 .574 & 1,53 \\
\hline$>25$ & 7.901 .222 & 5.844 .423 & 2.056 .799 & 1,35 \\
\hline
\end{tabular}

Sumber: Diolah dari SOUT 2014, BPS

\section{KESIMPULAN DAN SARAN}

\section{Kesimpulan}

Keadaan demografis petani kopi di OKUS saat ini pada umumnya berjenis kelamin laki-laki, tingkat pendidikan rendah, kepemilikan pohon cukup banyak 1.000-3.000 pohon dengan umur tanam kopi rataan 8-15 tahun. Keadaan perumahan atau tempat tinggal petani kopi di OKUS umumnya sudah baik untuk standar umum daerah pedesaan. Dari hasil penelitian tersebut dapat diambil kesimpulan usahatani di OKUS secara umum layak pada semua aspek terutama hukum, sosial ekonomi dan finansial. Perlu pengembangan dari sisi teknis dan manajemen karena memang ini masih usahatani rumah tangga tradisional sehingga aspek teknis dan manajemen belum maksimal dan belum berkembang modern.

Untuk aspek kelayakan finansial, rata-rata keuntungan/pendapatan petani kopi di OKUS dalam satu tahun adalah Rp 2.989.790 per hektar serta besarnya nilai $\mathrm{R} / \mathrm{C}$ rasio adalah 1,61 . Nilai $\mathrm{R} / \mathrm{C}$ ratio ini menunjukan bahwa setiap Rp 100 pengorbanan yang dikeluarkan oleh petani akan menambahkan penerimaan sebesar Rp 161. Hal ini berarti bahwa usahatani kopi di OKUS menguntungkan dan layak untuk diusahakan. Kelompok umur tanaman 5-7 tahun paling menguntungkan dengan $\mathrm{R} / \mathrm{C}$ rasio 1,98 atau keuntungan hampir 2 kali lipat.

\section{Saran}

Dari penelitian di atas, aspek kelayakan teknis dan manajemen masih perlu pengembangan baik dari pihak petani maupun pemerintah agar hasil usahatani kopi di OKUS lebih layak lagi. Perlu pemberdayaan dan dibentuk kelembagaan untuk para petani kopi seperti KUD dan kemitraan dengan perusahaan agar dapat menyelesaikan masalah paling dominan yaitu pemasaran kopi. Pemerintah, rumah tangga usahatani dan perusahaan hendaknya bersinergi agar semua aspek kelayakan dapat dipenuhi dengan secara optimal bahkan diharapkan lebih berdaya saing ke 


\section{STUDI KELAYAKAN USAHATANI KOPI DAN KARAKTERISTIK RUMAH TANGGA USAHATANI KOPI DI KABUPATEN OGAN KOMERING ULU SELATAN \\ Dana Megayani}

tingkat internasional karena tanaman kopi

di OKUS ini sudah merupakan produk unggulan di tingkat provinsi dan nasional. Saran untuk penelitian lanjutan dari aspek kelayakan finansial $\mathrm{B} / \mathrm{C}$ rasio yang tidak dapat diukur di sini karena penelitian ini hanya mencakup semua petani kopi yang telah menghasilkan buah kopi.

\section{DAFTAR PUSTAKA}

BPS. 2014. Potensi Pertanian Sumatera Selatan Analisis Hasil Pendataan Lengkap Sensus Pertanian 2013. Palembang: Badan Pusat Statistik Provinsi Sumatera Selatan.

Fanggi, R. 2016. Upaya Perlindungan Hukum Terhadap Pekerja Perkebunan Kopi di Kabupaten Jember. Jurnal Panorama Hukum 1(2): 69-82. https://doi.org/ 10.21067/ jph.v1i2.1417.

Hariance, R., Febriamansyah, R. dan Tanjung, F. 2016. Strategi Pengembangan Agribisnis Kopi Robusta di Kabupaten Solok. AGRISEP 15(1): 111-126.

Kaizan, Bustanul, A. dan Santoso, H. 2014. Kelayakan Finansial dan Nilai Ekonomi Lahan (Land Rent) Pada Penggantian Usaha Tani Kopi Menjadi Karet di Kabupaten Way
Kanan Provinsi Lampung. JIIA 2(4): 308-315.

Mardani, T. M. Nur, Satriawan H. 2017. Analisis Usaha Tani Tanaman Pangan Jagung di Kecamatan Juli Kabupaten Bireuen. Jurnal $S$. Pertanian 1(3): 203-204.

Muin, M. 2017. Pengaruh Faktor Produksi Terhadap Hasil Produksi Merica di Desa Era Baru Kecamatan Tellulimpoe Kabupaten Sinjai. Jurnal Economix 5(1): 203214.

Purwadi, M.A. 2018. Budidaya Tanaman Kopi Arabika Sebagai Pendorong Ekonomi Masyarakat di Kabupaten Intan Jaya. Jurnal Manajemen dan Bisnis 2(1): 1-11.

Nopriyandi, R. dan Haryadi. 2017. Analisis Ekspor Kopi Indonesia. Jurnal Paradigma Ekonomika 12(1): 1-10.

Saputra, A., Ismayani dan Romano. 2015. Strategi Pengembangan Kluster Perkebunan Kopi dan Tebu Untuk Pengembangan Ekonomi Kabupaten Aceh Tengah. Jurnal Agrisep 16(2): 38-47.

Suliyanto, 2010 Studi Kelayakan Bisnis, Yogyakarta : Penerbit Andi.

Turnip, C. 2002. Analisis Faktor-faktor yang Mempengaruhi Penawaran Ekspor dan Aliran Perdagangan Kopi Indonesia. Skripsi. Jurusan Ilmu-Ilmu Sosial Ekonomi, Fakultas Pertanian, Institut Pertanian Bogor. 